\title{
SERUM IRON DETERMINATION
}

\author{
BY \\ D'A. KOK AND F. WILD \\ From the Department of Medicine, University of Cambridge
}

(RECEIVED FOR PUBLICATION JANUARY 18, 1960)

\begin{abstract}
A simple, rapid, and sensitive mathod for the determination of iron in serum or plasma is described.

The procedure is carried out at room temperature with $2 \mathrm{ml}$. of serum or plasma, or with $1 \mathrm{ml}$. if high values are expected; it can be applied to turbid or jaundiced samples, whether previously frozen or not.

An ethanolic solution of 4:7-diphenyl-1:10-phenanthroline is used to produce a coloured iron complex, the optical density of which can be measured in any suitable photometer, using either 10 or $20 \mathrm{~mm}$. fused glass cuvettes or matched tubes of $1.1 \mathrm{~cm}$. internal diameter.
\end{abstract}

Methods for the determination of serum or plasma iron have been reviewed by Heilmeyer and Plötner (1937), Hemmeler (1951), Laurell (1952), and Ramsay (1958). Wet ashing procedures have for many years given the most dependable results, but the labour involved in their performance is considerable. Most of the methods in routine use are based on Barkan's (1927) observation that adding acid to plasma liberates iron from the protein with which it is normally bound; the proteins are then precipitated, either by heat or by the addition of trichloracetic acid, and the iron is determined colorimetrically after the addition of some substance which will form a coloured complex with the free iron.

Dissociation of the plasma iron-protein complex (transferrin) has usually been effected by adding hydrochloric acid, the final concentration of which has varied from $0.1 \mathrm{~N}$ to $2 \mathrm{~N}$.

A proportion of the liberated iron may be lost by adsorption on to insoluble protein during the precipitation process, especially if the preparation has been heated. This was demonstrated by Hill in 1930. He showed that it could be prevented by adding a reducing agent and by maintaining the $p \mathrm{H}$ at about 4 with an acetate buffer. His observations were confirmed by Fowweather (1934) and by Tompsett (1934) using different techniques, but were then lost sight of for some years.

Laurell (1952) pointed out that the optimal $p \mathrm{H}$ for achieving the rapid conversion of ferric to ferrous ions varies with the reducing agent used, and that, in the case of hydrazine sulphate, thioglycollic acid, and sodium dithionite, a $p \mathrm{H}$ of 4.5 to 4.9 is most suitable. This can most simply be maintained by buffering with a saturated solution of sodum acetate (Tompsett and McAllister, 1949).

Utilizing these principles, Ramsay (1953) obtained results which were $30-60 \mu \mathrm{g} . / 100 \mathrm{ml}$. higher than those obtained from the same specimens when using several of the older methods. This was confirmed by Peters, Giovanniello, Apt, and Ross (1956), who also showed that in the presence of a reducing agent dilute hydrochloric acid gave complete iron recovery from specimens which had previously been frozen.

Thiocyanate, $\alpha \alpha^{\prime}$-dipyridyl, and $1: 10$-phenanthroline have chiefly been used to form coloured complexes with the extracted iron. As the molar extinction coefficients of these substances are relatively low, the reactions have not been very sensitive, particularly in those methods in which large volumes of reagents have been used; they have also been unsatisfactory when the sera to be examined have been turbid or jaundiced.

A new reagent, 4:7-diphenyl-1:10-phenanthroline, or bathophenantbroline, was introduced by Case in 1951, and was applied to the estimation of serum iron by Peterson (1953). Its molar extinction coefficient is more than twice that of the previously used reagents. The iron complex formed with it is insoluble in water but soluble in alcohol. Extraction with alcohol can therefore both concentrate the complex and separate it from alcohol-insoluble substances which interfere with the colour, thus increasing the sensitivity of the reagent.

Trinder (1956) has prepared a sulphonated derivative of bathophenanthroline which forms a water-soluble compound with iron and has proved 
to be slightly more sensitive than the parent substance.

Peters et al. (1956) have described a simple method which can be performed at room temperature, and in which the coloured ironbathophenanthroline complex is developed in a single phase of water, isopropanol, and isoamyl alcohol. Complete iron recoveries were achieved. When their method was used at room temperature in Cambridge, the final solution was frequently found to be unstable, causing turbidity. This difficulty was overcome by dissolving the bathophenanthroline in ethyl alcohol. It was then decided to find out whether the estimation could be performed more quickly and without loss of simplicity or sensitivity.

\section{Experimental Procedures}

Hydrochloric Acid Concentration.-Assuming that the speed of dissociation of the serum iron-protein complex is related to $p \mathrm{H}$, and bearing in mind the fact that a proportion of the liberated iron may be lost by adsorption on to insoluble proteins, it was thought reasonable to use the maximum concentration of hydrochloric acid which could be added to serum without precipitating the proteins.

This was determined by adding $1 \mathrm{ml}$. volumes of hydrochloric acid of increasing normality to $2 \mathrm{ml}$. volumes of serum at room temperature. The results showed that a final concentration of about $0.6 \mathrm{~N}$ hydrochloric acid would be satisfactory.

Protein Precipitation.-Although an excess of trichloracetic acid is necessary to ensure complete precipitation of the serum proteins once the bound iron has been liberated, the total amount of acid which can be used is limited by the necessity of obtaining a minimal final volume, with a $p \mathrm{H}$ ranging between 4.5 and 4.9. Laurell (1952) pointed out that when hydrazine sulphate, thioglycollic acid, and sodium dithionite are used as reducing substances, this $p \mathrm{H}$ range is optimal for the rapid conversion of ferric to ferrous ions. It also allows the maximal intensity of colour to be most rapidly developed by the ironbathophenanthroline complex (personal observation).

The smallest quantity of trichloracetic acid necessary to precipitate the proteins completely was therefore determined by adding varying amounts of $40 \%$ trichloracetic acid to mixtures of $2 \mathrm{ml}$. of serum and $1 \mathrm{ml}$. of $2 \mathrm{~N}$ hydrochloric acid. These were stirred vigorously for \pm 45 seconds, and centrifuged for 10 minutes at 2,500 r.p.m. Each supernatant solution was decanted, treated with $0.1 \mathrm{ml}$. of $40 \%$ trichloracetic acid, and examined photometrically for the development of a further precipitate. The addition of $0.2 \mathrm{ml}$. or less of $40 \%$ trichloracetic acid was found to produce incomplete precipitation of the proteins.

It was concluded that treatment of $2 \mathrm{ml}$. of serum with $1 \mathrm{ml}$. of $2 \mathrm{~N}$ hydrochloric acid and $0.5 \mathrm{ml}$. of $40 \%$ trichloracetic acid (producing a final concentration of $0.572 \mathrm{~N}$ hydrochloric acid and allowing for an excess of trichloracetic acid) would be likely to extract the bound iron completely.

Recovery Experiments. - The validity of this hypothesis was assessed by means of a series of recovery experiments, using radioactive iron previously bound to the transferrin of the samples employed.

${ }^{50} \mathrm{Fe}$ was obtained from the Atomic Energy Establishment at Harwell, and $0.5 \mu \mathrm{c}$., containing not more than $0.4 \mu \mathrm{g}$. of elemental iron, was added to $25 \mathrm{ml}$. of serum and incubated at $37^{\circ} \mathrm{C}$. for one hour. The binding of the ${ }^{59} \mathrm{Fe}$ with the transferrin and the absence of free ${ }^{59} \mathrm{Fe}$ was shown in each case by autoradiography after electrophoresis on paper. The radioactivity of the initial samples and of the respective supernatant fractions, obtained after the addition of $2 \mathrm{~N}$ hydrochloric acid and precipitation of the proteins with trichloracetic acid, was counted in a well-type scintillation counter. Total counts of 20,000 to 40,000 were obtained from each specimen, and the standard error of counting was found not to exceed $0.7 \%$. The radioactivity of the supernatant

TABLE I

RESULTS OF ${ }^{50}$ FE RECOVERY EXPERIMENTS

\begin{tabular}{|c|c|c|c|c|c|c|c|c|c|c|c|}
\hline \multicolumn{2}{|c|}{ Serum* } & \multicolumn{2}{|c|}{$\mathrm{HCl}$} & \multicolumn{2}{|c|}{ TCA } & \multirow{2}{*}{ TGA } & \multirow{2}{*}{$\begin{array}{l}\text { Final } \\
\text { Concen- } \\
\text { tration } \\
\text { of } \mathrm{HCl}\end{array}$} & \multirow{2}{*}{$\begin{array}{l}\text { Final } \% \\
\text { of TCA }\end{array}$} & \multicolumn{2}{|c|}{$\%^{59} \mathrm{Fe}$ Recovery } & \multirow{2}{*}{$\begin{array}{c}\text { No. of } \\
\text { Tests }\end{array}$} \\
\hline State & Volume & Volume & Normality & Volume & $\%$ & & & & Range & Average & \\
\hline $\begin{array}{c}\text { Fresh } \ldots \\
,, \\
\text { Frozen } \\
\text {,. } \\
\text {," } \\
\text {," } \\
\text {,", } \\
\text {," }\end{array}$ & $\begin{array}{r}4 \\
2 \\
2 \\
2 \\
2 \\
2 \\
2 \\
2 \\
2 \\
2+4 \underset{\mathbf{H}_{2} \mathrm{O}}{2+4} \mathbf{H}_{2} \mathrm{O}\end{array}$ & $\begin{array}{l}1 \\
1 \\
1 \\
1 \\
1 \\
1 \\
1 \\
1 \\
1 \\
1 \\
1 \\
0\end{array}$ & $\begin{array}{l}2 \\
2 \\
2 \\
2 \\
2 \\
2 \\
2 \\
2 \\
6 \\
2 \\
2 \\
0\end{array}$ & $\begin{array}{l}1.0 \\
1.0 \\
0.5 \\
0.25 \\
1.0 \\
0.5 \\
0.5 \\
1.0 \\
1.0 \\
1.0 \\
1.0 \\
1.0\end{array}$ & $\begin{array}{l}40 \\
40 \\
40 \\
40 \\
40 \\
40 \\
40 \\
20 \\
20 \\
40 \\
40 \\
40\end{array}$ & $\begin{array}{l}\bar{z} \\
\overline{-} \\
\bar{z} \\
\bar{z} \\
\bar{z} \\
\overline{-}\end{array}$ & $\begin{array}{l}0.33 \mathrm{~N} \\
0.50 \mathrm{~N} \\
0.57 \mathrm{~N} \\
0.615 \mathrm{~N} \\
0.50 \mathrm{~N} \\
0.57 \mathrm{~N} \\
0.57 \mathrm{~N} \\
0.50 \mathrm{~N} \\
1.50 \mathrm{~N} \\
0.25 \mathrm{~N} \\
0.25 \mathrm{~N} \\
0\end{array}$ & $\begin{array}{c}6 \cdot 66 \\
10 \cdot 0 \\
5 \cdot 72 \\
3 \cdot 07 \\
10 \cdot 0 \\
5 \cdot 72 \\
5 \cdot 72 \\
5 \cdot 0 \\
5 \cdot 0 \\
5 \cdot 0 \\
5 \cdot 0 \\
13 \cdot 3\end{array}$ & $\begin{array}{c}99 \cdot \overline{6-104 \cdot 2} \\
99 \cdot 0-102 \cdot 5 \\
0 \\
94 \cdot 5-96 \cdot 7 \\
96 \cdot 5-96 \cdot 7 \\
- \\
- \\
\overline{-} \\
90 \cdot 6-92 \cdot 0 \\
82 \cdot 9-83 \cdot 5\end{array}$ & $\begin{array}{r}94.0 \\
101.9 \\
100.9 \\
103.0 \\
95.6 \\
96.6 \\
101.5 \\
92.5 \\
93.6 \\
80.9 \\
91.3 \\
83.2\end{array}$ & $\begin{array}{l}1 \\
3 \\
6 \\
2 \\
2 \\
2 \\
1 \\
1 \\
1 \\
1 \\
2 \\
2\end{array}$ \\
\hline
\end{tabular}

* Either serum or plasma. TCA $=$ trichloracetic acid. TGA $=$ thioglycollic acid. † Stood at room temperature for 2 hr. before being centrifuged. 


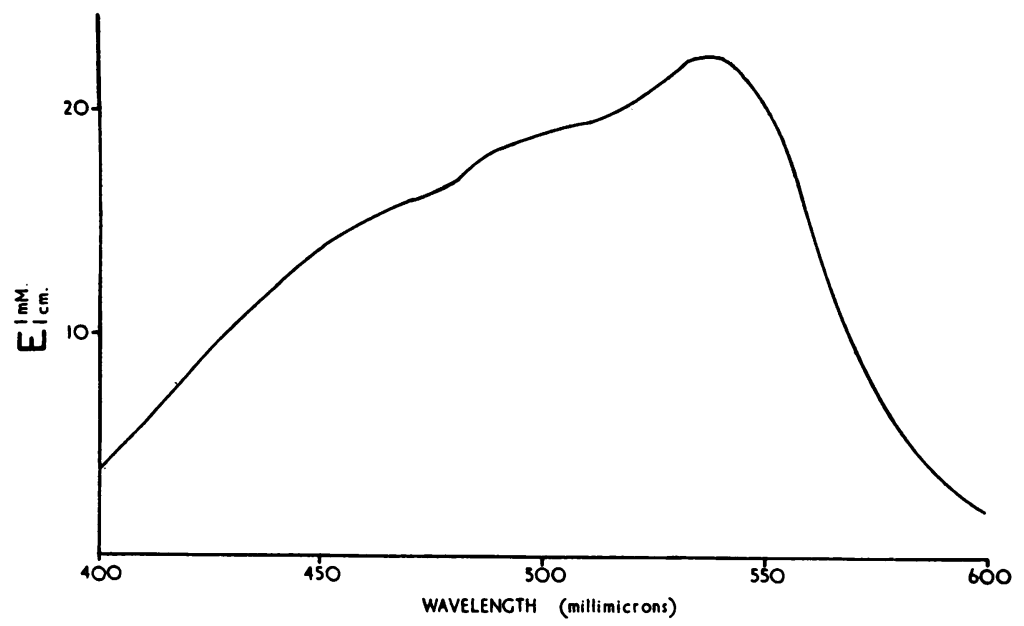

FIG. 1.-Absorption spectrum of the iron-bathophenanthroline complex, obtained by treating the standard iron solution and a reagent blank according to the procedure for serum iron determination described in the text. The optical densities were read in a " unicam" model S.P. 600 spectrophotometer, using $10 \mathrm{~mm}$. cuvettes.

fractions, corrected for dilution, was expressed as a percentage of that of the initial samples, and was considered to represent the recovery of iron. The correction factor described by Severinghaus and Ferrebee (1950) was not used.

These experiments showed that complete recovery of added ${ }^{59} \mathrm{Fe}$ could be obtained from fresh sera* after treatment with $0.5-0.6 \mathrm{~N}$ hydrochloric acid and $3-10 \%$ trichloracetic acid at room temperature. Previously frozen samples yielded incomplete recovery (92-96\%) when treated similarly; recovery was not improved by an increase in the concentration of hydrochloric acid to $1.5 \mathrm{~N}$, but was complete when thioglycollic acid was added to the mixture (Table I).

Adjustment of pH.-The amount of sodium acetate required to buffer the supernatant solution obtained from the mixture of $2 \mathrm{ml}$. of serum, $1 \mathrm{ml}$. of $2 \mathrm{~N}$ hydrochloric acid, and $0.5 \mathrm{ml}$. of $40 \%$ trichloracetic acid was investigated by adding increasing volumes of a saturated solution of sodium acetate of $2 \mathrm{ml}$. of the supernatant solution and measuring the $p H$ with a glass electrode (Pye model $605 \mathrm{pH}$ meter).

A final $p \mathrm{H}$ of 4.8 was obtained by adding $1 \mathrm{ml}$. of the sodium acetate to $2 \mathrm{ml}$. of the supernatant specimens.

Bathophenanthroline Solution. - An excess of bathophenanthroline is necessary in order to combine with all the iron likely to be present, and a concentration of $30 \%$ or more of alcohol is required to keep the resulting iron-bathophenanthroline complex in solution at room temperature. The addition of $1.5 \mathrm{ml}$. of a $0.04 \%$ solution of bathophenanthroline in absolute alcohol to the $3 \mathrm{ml}$. of buffered supernatant solution described above produced a clear solution. The colour was stable for at least 24 hours.

\footnotetext{
*Several deeply jaundiced samples were used. Completely clear supernatant solutions were obtained.
}

Photometric Characteristics. - The absorbance of the ironbathophenanthroline complex was investigated by treating $2 \mathrm{ml}$. volumes of increasing concentrations of a solution of ferric chloride in a similar manner. The curve was found to be linear to a concentration of just over $0.76 \mu \mathrm{g}$. Fe per ml. of the final solution, corresponding to $300 \mu \mathrm{g}$. Fe per 100 $\mathrm{ml}$. of the ferric chloride solution. The absorption spectrum showed a peak at 534 to 538 $\mathrm{m} \mu$ (Fig. 1), and the millimolar absorbance at $536 \mathrm{~m} \mu$ was found to be 22.4 .

\section{Proposed Method}

Iron-free Water.-Water for the preparation of all solutions and the rinsing of all acidwashed apparatus was distilled twice over a glass and passed through a de-ionizing resin column $\dagger$ before use.

Apparatus.-All the glass used, including the reagent bottles, was washed in a detergent solution, soaked in $50 \%$ hydrochloric acid for a minimum of 24 hours before use, and finally rinsed in iron-free water. Stainless steel needles were washed through with iron-free water.

A rubber bulb-type pipette filler ("hoslab" propipetteł) was used for accurate pipetting when necessary.

Reagents.-The following were used :

$2 \mathrm{~N} \mathrm{Hydrochloric} \mathrm{Acid.-Concentrated} \mathrm{hydrochloric}$ acid, $200 \mathrm{ml}$. (AnalaR, sp.g. 1.18) was diluted to 1 litre with water.

$40 \%$ Trichloracetic Acid.-This was distilled to remove traces of iron.

Thioglycollic Acid.-This was redistilled to remove traces of iron, which vary in amount in different specimens.

Saturated Solution of Sodium Acetate.-This was prepared from sodium acetate trihydrate (AnalaR). Iron contamination was removed by precipitation of the sodium acetate in ethyl alcohol in the cold, after $10 \mathrm{ml}$. of the bathophenanthroline reagent had been added to a super-saturated solution of $500 \mathrm{~g}$. at $37^{\circ} \mathrm{C}$.

4:7-Diphenyl-1:10-phenanthroline (Bathophenanthroline).-A $0.04 \%$ solution was made in ethyl alcohol (AnalaR).

Standard Iron Solutions.-One hundred milligrams of freshly cleaned pure iron wire were dissolved in

†Elgastat, Type B102, Elga Products Ltd., London, S.W.19.

$\ddagger$ Hospital and Laboratory Supplies Ltd., 12, Charterhouse Square, London, E.C.1 
$4 \mathrm{ml}$. of $50 \%$ hydrochloric acid, and diluted to 1 litre with water, to form a stock solution.

A dilute working solution, containing $1 \mu \mathrm{g}$. $\mathrm{Fe} / \mathrm{ml}$., was prepared.

Procedure.-This is as follows :

(a) For Values Not Exceeding $300 \mu \mathrm{g}$. per $100 \mathrm{ml}$.Two drops of thioglycollic acid were added to $2 \mathrm{ml}$. of serum in a $10 \mathrm{ml}$. conical centrifuge tube. The mixture was shaken briefly and $1 \mathrm{ml}$. of $2 \mathrm{~N}$ hydrochloric acid was then added, with further shaking. Next $0.5 \mathrm{ml}$. of $40 \%$ trichloracetic acid was added; the contents of the tube were stirred vigorously with a glass rod for \pm 45 seconds, and then centrifuged for 10 minutes at 2,500 r.p.m.

Two millilitres of the supernatant fluid were pipetted into a suitably stoppered tube, $1 \mathrm{ml}$. of saturated sodium acetate and $1.5 \mathrm{ml}$. of the bathophenanthroline reagent added, and the contents mixed by swirling. Iron standards containing 1 and $2 \mu \mathrm{g}$. Fe per $2 \mathrm{ml}$. respectively and a reagent blank using $2 \mathrm{ml}$. of water instead of serum were prepared in a similar manner.

(b) For Values Above $300 \mu \mathrm{g}$. per $100 \mathrm{ml}$.-One millilitre of serum, $0.5 \mathrm{ml}$. of $2 \mathrm{~N}$ hydrochloric acid, $0.25 \mathrm{ml}$. of $40 \%$ trichloracetic acid, $1 \mathrm{ml}$. of the supernatant solution, $0.5 \mathrm{ml}$. of saturated sodium acetate, and $3 \mathrm{ml}$. of the bathophenanthroline reagent were substituted for the quantities used above.

After full colour development had taken place (15-30 sec.) the optical densities of the serum extracts and standard iron solutions were read against the reagent blank in a " unicam model" S.P. 600 spectrophotometer at $536 \mathrm{~m} \mu$, using $10 \mathrm{~mm}$. fused glass cuvettes. The iron values were then read off from a previously calibrated graph prepared by plotting optical densities against concentrations of the standard iron solution. Any suitable photometric apparatus can be used instead of the above instrument.

The following optical density readings were obtained with a solution containing the equivalent of $100 \mu \mathrm{g}$. of iron per $100 \mathrm{ml}$., using cells of various types.

\begin{tabular}{ccc|c|c}
\hline \multicolumn{2}{c|}{ Cell } & & Final Volume (ml.) & Optical Density \\
\hline $1.1 \mathrm{~cm}$. tube & $\ldots$ & $\ldots$ & 4.5 & 0.095 \\
$10 \mathrm{~mm}$. cuvette & $\ldots$ & $\ldots$ & 4.5 & 0.1025 \\
$20,, \quad,{ }^{*}$ & $\ldots$ & $\ldots$ & 4.5 & 0.2025 \\
\hline
\end{tabular}

* Raised $0.5 \mathrm{~cm}$. in the cuvette holder.

It is preferable to use $20 \mathrm{~mm}$. cuvettes, so that the optical density readings may be brought within the range of the optimal sensitivity of the instrument.

\section{Comparative Readings}

The efficiency of the method was contrasted with that of Peters et al. (1956), by carrying out a series of four replicate analyses on three previously frozen
TABLE II

COMPARISON OF IRON VALUES OBTAINED BY PRESENT METHOD AND THAT OF PETERS ET $A L$. FROM THREE SAMPLES OF SERUM

\begin{tabular}{c|c|c}
\hline \multirow{2}{*}{$\begin{array}{c}\text { Serum } \\
\text { Sample }\end{array}$} & \multicolumn{2}{|c}{ Iron Values $(\mu \mathrm{g}$.$) per 100 \mathrm{ml}}$. \\
\cline { 2 - 3 } & Present Method & Peters et al. \\
\hline I & 72 & 70 \\
& 72 & 70 \\
& 72 & 69 \\
II & 71 & 70 \\
\hline III & 121 & 120 \\
& 121 & 120 \\
& 121 & 119 \\
& 192 & 120 \\
\hline & 192 & 191 \\
& 190 & 186 \\
& 190 & 186 \\
\hline
\end{tabular}

samples of serum, which contained low, average, and high amounts of bound iron respectively. The values obtained are listed in Table II and show good agreement and reproducibility.

\section{Discussion}

Peters et 'al. (1956) have extracted iron completely from fresh and from previously frozen sera, whether turbid or jaundiced, by using 0.12 $\mathrm{N}$ hydrochloric acid for 30 minutes at room temperature in the presence of thioglycollic acid.

Using $0.67 \mathrm{~N}$ hydrochloric acid at room temperature, with minimal incubation, Bothwell and Mallett (1955) also obtained complete recovery of iron. This was done in the absence of thioglycollic acid, which, in their method, was only added to the supernatant fluid obtained after precipitation of the proteins with trichloracetic acid. Ramsay (1957) employed their procedure to investigate the effects of varying concentrations of hydrochloric acid acting on serum for different lengths of time, and was unable to confirm their results. He found that $0.67 \mathrm{~N}$ hydrochloric acid resulted in incomplete iron extraction after 60 minutes' incubation at room temperature and that $1.0 \mathrm{~N}$ hydrochloric acid needed 20 minutes' incubation, at room temperature, to produce full recovery of iron.

The present studies have demonstrated that $0.6 \mathrm{~N}$ hydrochloric acid, as used in Bothwell and Mallett's procedure, does extract iron completely from fresh sera at room temperature and in the absence of a reducing agent, but that incomplete recoveries are obtained from stored specimens, unless the iron-protein complex is dissociated in the presence of thioglycollic acid.

Although not recorded, it is possible that Bothwell and Mallett may have used fresh sera 
and that Ramsay may have used stored samples in their respective investigations. If so, this might well account for the apparent contradictions stated above.

The sensitivity of the proposed method is slightly less $( \pm 5 \%)$ than that of Trinder's (1956) procedure, but is achieved without the complication of sulphonating the bathophenanthroline and of heating the reagent mixture. The sulphonated derivative has not yet been isolated as a definite substance of known structure and so it is difficult to account for its increased sensitivity other than by postulating an increase in the number of resonance structures.

\section{REFERENCES}

Barkan, G. (1927). Hoppl-Seyl. Z. physiol. Chem., 17I, 194. Bothwell, T. H., and Mallett, B. (1955). Biochem. J., 59, 599.

Case, F. H. (1951). J. Org. Chem., 16, 1541.

Fowweather, F. S. (1934). Biochem. J., 28, 1160.

Heilmeyer, L., and Plotner, K. (1937). Das Serumeisen und die Eisenmangelkrankheit. Fischer, Jena.

Hemmeler, G. (1951). Métabolisme du Fer. Masson, Paris.

Hill, R. (1930). Proc. rov. Soc. B., 107, 205.

Laurell, C. B. (1952). Pharmacol. Rev., 4, 371.

Peters, T., Giovanniello, T. J., Apt, L., and Ross, J. F. (1956). J. Lab. clin. Med., 48, 280.

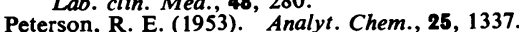

Peterson, R. E. (1953). Analyt. Chem., 25, 1337.
Ramsay, W. N. M. (1953). Biochem. J., 53, 227.

(1957). Clin. Chim. Acta, 2, 214.

- (1958). In Advances in Clinical Chemistry, Vol. 1, p. 1, ed. Harry Sobotka and C. P. Stewart. Academic Press, New York and London.

Severinghaus, J. W., and Ferrebee, J. W. (1950). J. biol. Chem., 187,

621.
Tompsett, S. L. (1934). Biochem. J., 28, 1536.

- and McAllister, R. A. (1949). Analyst, 74, 315.

Trinder, P. (1956). J. clin. Path., 9, 170. 